\title{
TRAUMATIC HAEMARTHROSIS CAUSING FEMORAL HEAD SUBLUXATION
}

\author{
K. C. GOPALAKRISHNAN, J. LEWIS
}

From the Medical College Hospital, Kerala, India and Glan Clwyd Hospital, Wales

\begin{abstract}
We report seven children in whom traumatic haemarthrosis of the hip had produced lateral subluxation of the femoral head, which is different from the apparent displacement seen in Perthes' disease. In all seven cases, aspiration of the haemarthrosis allowed reduction of the femoral head, and follow-up for a mean of 14 months revealed no evidence of avascular necrosis of the proximal femoral epiphysis.

Traumatic haemarthrosis of the hip in children appears to be a clinical entity which can produce femoral head subluxation. Aspiration and traction is the treatment of choice and can cure the condition.
\end{abstract}

Haemorrhage into the hip can increase intracapsular pressure and produce ischaemia of the femoral head (Soto-Hall, Johnson and Johnson 1964; Deyerle 1980; Minikel, Sty and Simons 1983; Wingstrand et al 1986), but conventional radiographs of these cases give little information about intra-articular effusion (Brown 1975). The routine use of ultrasonography and computed tomography is often recommended (Strömqvist et al 1985; Wingstrand et al 1986; Wingstrand, Egund and Forsberg 1987). We report seven children in whom conventional radiographs of the hips showed unequivocal signs of an intra-articular effusion.

\section{PATIENTS AND RESULTS}

Five boys and two girls were admitted to hospital with pain and marked restriction of hip movement after injuries sustained by falls from a height. On admission, one to Glan Clwyd Hospital, north Wales and six to the Medical College Hospital, Kottayam, in south India, they were shown to have traumatic haemarthroses with femoral head subluxation. All the children had $15^{\circ}$ to $20^{\circ}$ hip flexion deformity. The initial radiographs taken in this position, therefore, showed slight asymmetry.

K. C. Gopalakrishnan, MCh(Orth), MS(Orth), Assistant Professor of Orthopaedics

Medical College Hospital, Kottayam, Kerala, Republic of India.

J. Lewis, FRCS, Consultant Orthopaedic Surgeon

Glan Clwyd Hospital, Bodelwyddan, Rhyl, Clwyd, Wales.

Correspondence should be sent to Dr K. C. Gopalakrishnan.

(C) 1990 British Editorial Society of Bone and Joint Surgery $0301-620 \mathrm{X} / 90 / 4122 \$ 2.00$

J Bone Joint Surg [ Br] 1990; 72-B : 554-6.
The mean age of the patients was 3.9 years (range 1 year 10 months to 5 years). None had any previous symptoms referrable to the hip and all were otherwise healthy, with no history of any bleeding disorder in their families. The mean interval between injury and aspiration of the hip was 31.4 hours (range 10 to 72 ).

Table I. Details of seven cases of traumatic haemarthrosis of the hip treated by aspiration and traction

\begin{tabular}{|c|c|c|c|c|c|c|}
\hline \multirow[b]{2}{*}{ Case } & \multirow{2}{*}{\multicolumn{2}{|c|}{$\begin{array}{l}\text { Age and sex } \\
\text { yr mth }\end{array}$}} & \multirow{2}{*}{$\begin{array}{l}\text { Delay before } \\
\text { aspiration (hr) }\end{array}$} & \multicolumn{2}{|c|}{$\begin{array}{l}\text { Medial joint } \\
\text { space (mm) }\end{array}$} & \multirow{2}{*}{$\begin{array}{l}\text { Volume of } \\
\text { blood } \\
\text { aspirated } \\
\text { (ml) }\end{array}$} \\
\hline & & & & Before & After & \\
\hline $1^{*}$ & 110 & $\mathbf{M}$ & 10 & 18 & 7 & 11 \\
\hline 2 & 35 & $\mathbf{F}$ & 72 & 18 & 8 & 9 \\
\hline 3 & 38 & $\mathbf{F}$ & 12 & 20 & 7 & 28 \\
\hline 4 & 49 & $\mathbf{M}$ & 24 & 16 & 6 & 14 \\
\hline 5 & 47 & $\mathbf{M}$ & 36 & 17 & 8 & 18 \\
\hline 6 & 50 & $\mathbf{M}$ & 18 & 16 & 7 & 15 \\
\hline 7 & 44 & $\mathbf{M}$ & 48 & 14 & 6 & 10 \\
\hline
\end{tabular}

* physeal widening, treated in a hip spica

On the initial anteroposterior radiograph the inferomedial joint space was measured from the medial border of the 'tear drop' to the proximal femoral metaphysis. A significant increase in comparison with that on the uninjured side was recorded. After aspiration of the hip one child was immobilised in a single spica plaster for six weeks, because of the diagnosis of a Salter Harris type I 


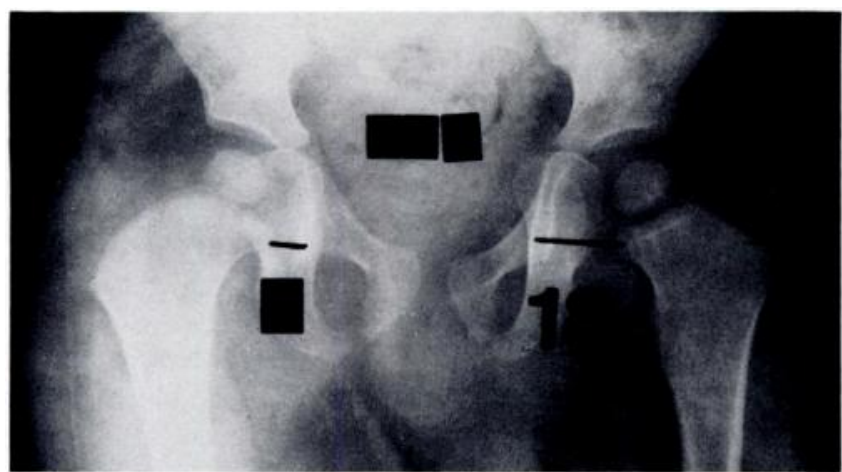

Fig. 1

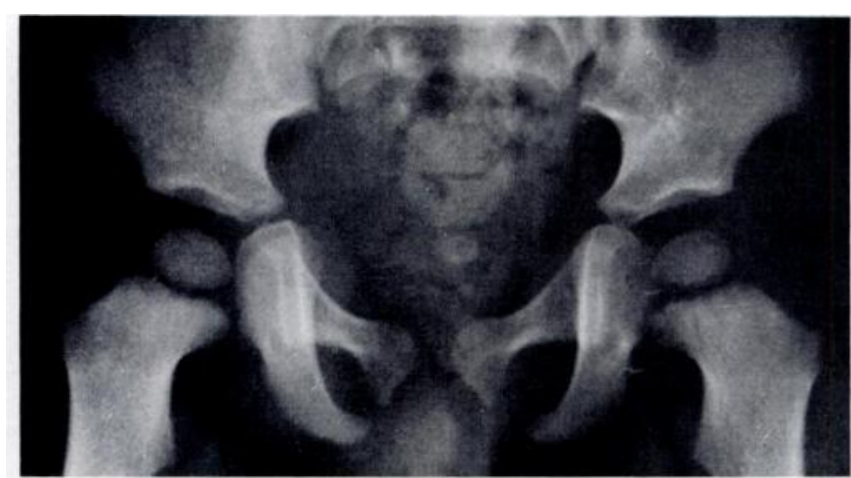

Fig. 2

Case 1. Figure 1 - Radiograph before aspiration showing an increase in the medial joint space and widening of the proximal femoral physis. Figure 2 - Radiograph after removal of the hip spica at six weeks.

injury of the proximal femoral epiphysis (Fig. 1). The other six were treated by bed rest and above-knee skin traction. Traction was applied with the leg on a pillow to allow about $20^{\circ}$ of hip flexion and was continued until full pain-free extension of the hip was possible. This was achieved in five to seven days; traction was then continued in the neutral position for an average of 14 days (10 to 21). After removal of traction or plaster the children were free in bed for three or four days before starting weight-bearing. At this stage, none had any recurrence of pain or abnormal signs in the hip.

All seven patients had some femoral head subluxation (Table I); the amount of blood aspirated varied from 9 to $28 \mathrm{ml}$ (average $15 \mathrm{ml}$ ). After aspiration, radiographs showed relocation of the femoral heads with normal inferomedial joint spaces (Figs 1 to 4).

Follow-up. The mean follow-up was 21.4 months (range 14 to 36 ). Clinical and radiographic examination showed no evidence of avascular necrosis of the femoral head. The height and width of the ossific head nucleus measured on anteroposterior and Lauenstein lateral views were the same as those on the normal side.

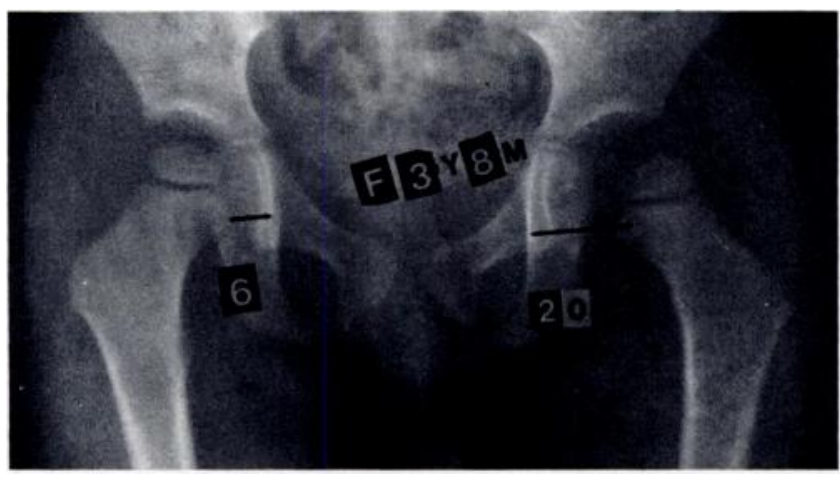

Fig. 3

\section{DISCUSSION}

The radiographic finding of an increase in the medial joint space has been regarded as an early sign of Perthes' disease, and is believed to show an apparent subluxation due to enlargement of the cartilaginous femoral head displacing the ossific nucleus laterally (Catterall 1982). In all our cases the obvious radiological sign was such an increase in the medial joint space, but this was proved to be due to true subluxation. The correct diagnosis can be made by careful evaluation of the symptoms and clinical signs. Significant trauma had always occurred, and there was marked painful restriction of all active and passive movement in contrast with the differential limitation characteristic of Perthes' disease.

Trueta (1957) considered that many hip disorders and particularly those of the femoral head during growth are vascular in origin. Branches from the medial and lateral femoral circumflex arteries pierce the capsule at its trochanteric attachment and run along the femoral neck to the head of the femur. With growth these vessels are increasingly incorporated into fibro-osseous canals (Kemp 1981), but in very young children most of these

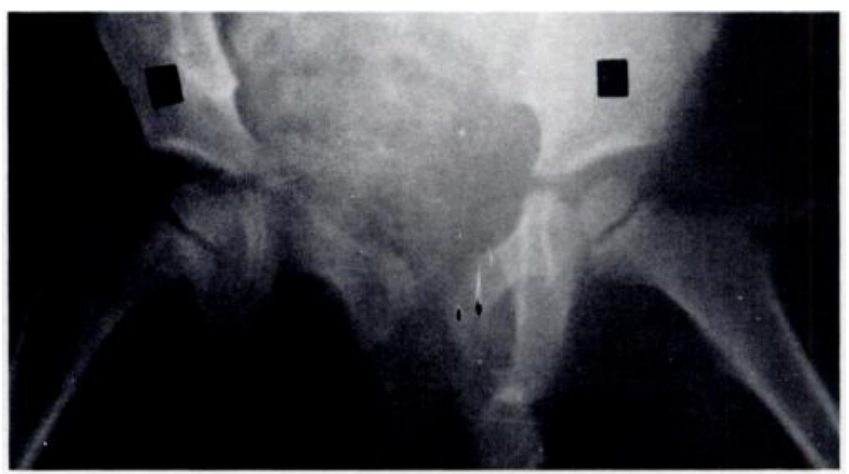

Fig. 4

Case 3. Figure 3-Radiograph showing considerable lateral displacement of the left femoral head. Figure 4 - Radiograph after aspiration of $28 \mathrm{ml}$ of blood. 
vessels lack this support and may be injured even when there is no obvious bony or cartilaginous damage. Children under about six years of age thus run a risk of damage to the retinacular vessels by injuries usually insufficient to produce a hip fracture or dislocation. The haemarthrosis which may result will increase until the intracapsular pressure exceeds the anteriolar pressure; this rise in intra-articular pressure may be sufficient to produce lateral subluxation of the hip.

In all our cases, aspiration of the haemarthrosis allowed reduction of the femoral head with significant relief of pain and the return of some pain-free hip movement which improved to near normal within a few days. We consider that traction should be given in $20^{\circ}$ to $30^{\circ}$ hip flexion until full extension of the hip is painless.
The likely complication of raised intra-articular pressure in the hip from blood, synovial fluid or pus is avascular necrosis; the duration of absolute or relative ischaemia which will cause residual damage to the femoral head is unknown. None of the children we report showed any evidence of avascular necrosis at a mean of 14 months follow-up and we consider that subsequent changes are unlikely.

We conclude that in children, femoral head subluxation can be produced by a tense haemarthrosis and it is totally reversible by aspiration.

No benefits in any form have been received or will be received from a commercial party related directly or indirectly to the subject of this article.

\section{REFERENCES}

Brown I. A study of the "capsular" shadow in disorders of the hip in children. J Bone Joint Surg [Br] 1975; 57-B:175-9.

Catterall A. Legg-Calvé-Perthes disease. (Current problems in orthopaedics). Edinburgh, etc: Churchill Livingstone, 1982.

Deyerle WM. Impacted fixation over resilient multiple pins. Clin Orthop $1980 ; 152: 102-22$.

Kemp HBS. Perthes' disease : the influence of intracapsular tamponade on the circulation in the hip joint of the dog. Clin Orthop 1981; $156: 105-14$.

Minikel J, Sty J, Simons G. Sequential radionuclide bone imaging in avascular pediatric hip conditions. Clin Orthop 1983; 175: 202-8.
Soto-Hall R, Johnson LH, Johnson RA. Variations in the intra-articular pressure of the hip joint in injury and disease. J Bone Joint Surg [Br] 1964; 46-A :509-16.

Strömqvist B, Wingstrand $\mathbf{H}$, Egund $\mathbf{N}$, et al. Traumatic hip joint tamponade. Acta Orthop Scand 1985; $56: 81-5$.

Trueta J. The normal vascular anatomy of the human femoral head during growth. J Bone Joint Surg [Br] 1957; 39-B:358-94.

Wingstrand H, Egund N, Forsberg L. Sonography and joint pressure in synovitis of the adult hip. J Bone Joint Surg [Br] 1987; 69-B: 254-6.

Wingstrand H, Strömqvist B, Egund N, Gustafson T, Nilsson LT, Thorngren KG. Hemarthrosis in undisplaced cervical fractures. Acta Orthop Scand 1986; 57:305-8. 